\title{
Parenting Skills and Non-compliance: Parent Training for Families with Mildly Mentally Retarded Children
}

\author{
Patrizia Oliva*, Sebastiano Costa, Francesca Cuzzocrea
}

Department of Human and Social Sciences, University of Messina, Messina, 98100, Italy

\begin{abstract}
The aim of this research was to explore parent-child interaction processes. In particular, parent training was experimented in order: a) to modify parents' misguided beliefs about mental retardation and children's behavioural problems; b) to reduce parental stress and increase parenting skills. 28 couples of parents with mentally retarded children were tested. The experimental group was trained in communication and self-regulation strategies, and behavioural and educational techniques for child management. The results proved the efficacy of parent training. Compared to parents in the control group, those in the experimental group showed marked changes in their perception of children's problems, lower stress level and greater parental competences.
\end{abstract}

Keywords Non-compliant behavior, Mental Retardation, Parent Training

\section{Introduction}

When children are not compliant, oppositional and deliberately misunderstand what their parents request of them, the parent-child relationship can become critical and characterised by negative emotions. In these families, the quality of parenting is severely compromised, impairing the overall family functioning[1-3]. The persistent stress condition that characterises daily interactions can also have an impact on the psychological state of family members, which may put individuals at risk of social isolation. Several studies have shown that the persistence of these conditions can lead to antisocial behaviours in children and to family disintegration[3-5]: a vicious circle from which it can be very difficult to find a way out. On the one hand, children's non-compliance and impulsive behaviour are more likely to be found in the context of harsh parenting or dysfunctional family relationships. On the other, the persistence of children's inappropriate behaviour challenges parental tolerance and self-efficacy, causing them to use coercive educative practices which reinforce rather than put an end to their children's improper behaviour[6]. Inconsistent or rejecting parents are unable to adequately monitor their children's activities and promote positive conduct, be it overly harsh or overly permissive, increase the probability of the development and maintenance of problems in their children[7]. Even more critical is the situation in families with mental or physically disabled

* Corresponding author:

poliva@unime.it (Patrizia Oliva)

Published online at http://journal.sapub.org/edu

Copyright $\odot$ year Scientific \& Academic Publishing. All Rights Reserved children[8].

Children with mental disabilities often exhibit non compliant behaviours and their educative management, already difficult in itself, becomes particularly challenging, exposing parents to higher levels of stress[9-10], and reducing their coping skills[11]. Disability can highlight the family's difficulty in child management and often poor parenting skills cause a greater negative effect on the child's behaviour than the illness itself. A child in need of total parental care and support can have serious consequences for both parents and family members[12], modifying their life styles[13]. Furthermore, everyday problems and the parents' sense of helplessness not only affect the quality of relationships with the external environment[14], but, more importantly, perceived stress also has an adverse impact on the quality of interaction between spouses and their other children[15-17]. Nevertheless, if efficiently supported and trained, most families, even the most problematic ones, are able to function in an adaptive way, learning to use effective coping strategies to manage stressful, sometimes very complex, family situations[18]. As is well known, working with children without involving their parents is not really successful[19-20]. A child's behaviour, whether normal, deviant or delayed, is strongly influenced by interactions with his social environment and by people who are important to him[21-24]. Thus, when the family relation patterns are dysfunctional, it is essential that family members, especially parents, acquire the resources and educational, emotional and social skills to interact more functionally with their child[25]. Studies highlight the need to improve parent-child relationships, teaching parents to pay more attention to children's positive behaviours[26]. In this sense, parent training, especially in highly 
dysfunctional and at risk families, may represent a "therapeutic" element and a form of prevention[22, 27-28]. Parent intervention seems, therefore, to be able to reduce children's behavioural problems and prevent the onset of deviant behaviour in later stages of life[29-31]. When oppositional behaviours characterise the interactions of parents with a disabled child, parent education programmes have to be adapted to the particular needs of the family context and the child's disability[32]. Among the numerous parent training programmes, the behavioural type seems to be more efficient than others when supporting these multi-problematic families[33-35]. The main purpose of the training is to reverse the family's coercive patterns, correct inadequate and dysfunctional parenting styles and, through a careful analysis of family dynamics, explain and correct non-compliant child behaviour. Several researchers have tested the effectiveness of specific interventions to reduce oppositional behaviour in children with developmental disabilities, which, compared to traditional approaches, focus mainly on "positive techniques" (e.g., reinforcement of appropriate behaviours, educational consistency, assertive communication), reducing the use of "punishment techniques" such as, time-out[23, 36-37]. It has been shown that punitive or inconsistent educational practices can have a negative impact on the child's early psychological functioning (aggressive behaviour acquisition and anxiety, low self-esteem) with significant later consequences (substance and alcohol abuse, delinquency and academic failures)[38]. Through behavioural parent training, parents and children learn how to interact in a more functional, adaptive and constructive way. Learning to modify contingencies, parents can establish positive interactions with their children; favouring compliance in the short-term, while in the long-term they seem to produce significant changes in the family system[39]. Once acquired, these interaction patterns seem to become generalised in other environments and contexts and are maintained over time [25-26, 40]. Obviously, parent training is not only structured to remove the child's dysfunctional behaviours, but aims to promote functional family relationships[26]. Specifically, behavioural parent training, based on the principles of behaviour analysis and social learning, is a therapeutic strategy that aims to teach parents how to apply parental management strategies, they modify their behaviour because it produces a behavioural change in the child. Reference[35] identifies four distinct but related components that characterise behavioural parent training (BPT). First, the conceptual framework of the BPT is derived from the learning theory, in particular from the operating conditioning model[41-42], and from social learning theory[43]. Secondly, the BPT includes a variety of principles and general assumptions about the relationship between behaviour and events that precede or follow the behaviour. From these principles, a series of techniques of behaviour modification is created. Many of the educational skills are learned by parents through active training, which takes into account the use of role-playing, feedback behaviour, modelling, etc. Finally, the BPT programme integrates systematic procedures for assessment and evaluation to determine the progress of both parents and children. The continuous monitoring of the skills learned allows the trainer to check, in progress, the treatment effectiveness and to evaluate the possibility to make functional changes for its successful outcome Several studies have confirmed the positive effects of this treatment on children and parent functioning in terms of improving the child's behavioural problems [44] and increased positive parent/child interactions[45-46]. It is true that, from a systemic perspective, a more functional family environment affects the well-being of all family members, improving the individual and family levels of resilience[47-48]. In particular, it seems that behavioural parent training has a positive impact on marital satisfaction[49], reducing anxiety and parental stress[45], and maternal depression[50-51], increasing parental self-efficacy[44]. Early interventions and support programmes for the couple and family, especially for those at risk, would therefore prevent psychological distress from occurring or, at any rate, activate the resources necessary to safeguard individual and family well-being.

The aim of this study was to verify the efficacy of behavioural parent training for parents with mentally retarded and non-compliant children. In particular, the programme aimed to change parents' misguided beliefs about their children's non-compliant behaviours, improving the parenting style and encouraging more functional family interactions.

\section{Methods}

\subsection{Participants}

28 parents, 14 fathers (age: $\mathrm{M}=40.21, \mathrm{SD}=6.30$ ) and 14 women (age: $\mathrm{M}=36, \mathrm{SD}=4.45$ ) took part in the research. In all selected families there was a child (age: $\mathrm{M}=7.5, \mathrm{SD}=$ 2.36) with mild mental retardation, diagnosed by a competent medical authority (ASP), about whom the parents complained of non-compliant behaviour On the basis of their willingness to attend parent training and, in any case, to participate in the research, parents were randomly assigned to two different groups: an "parent training group" made up of 14 couples who attended the training, and a "control group" consisting of the remaining 14 couples who completed the questionnaires, during pre-training and post training phases.

\subsection{Measures}

HSQ - Home Situations Questionnaire[52] - This questionnaire was administered to parents, assessing the pervasiveness and severity of the child's behavioural problems in 16 different domestic situations.

$P S Q$ - Parent Symptom Questionnaire [53] - This checklist consists of 93 items which describe the most common behaviours associated with behavioural disorders. Scores are expressed on a 4-point Likert scale (never, sometimes, often 
and always). Parents indicate how often their children exhibit the behaviours being studied.

QVCE-Assessment Questionnaire of Educational Skills [54; 55] - This questionnaire estimates if and how parents of school-age children use contingency management methods. The total score provides an indication of the knowledge and proficient use of behavioural modification techniques.

PSI-Parent Stress Index[56] - This questionnaire for parents evaluates the magnitude of stress in the parent-child system. It is a 120 -item inventory that focuses on two major domains of stress: child characteristics and parent characteristics. Within the Child Domain, six sub-scales (Distractibility / Hyperactivity, Adaptability, Parent Reinforcement, Demandingness, Mood, and Acceptability) evaluate sources of stress which are taken from the parent's report of child characteristics. Within the Parent Domain, seven sub-scales (Competence, Isolation, Attachment, Health, Role Restriction, Depression, and Spouse/Parenting Partner Relationship) measure sources of stress related to parent characteristics. Two domains, Child and Parent, combine to form the Total Stress scale. Parents must indicate their level of agreement on a 5-point Likert scale (strongly agree, agree, not sure, disagree, strongly disagree).

\subsection{Procedure}

The research was carried out in three phases: pre-training, training, post-training.

In the pre-training, selected questionnaires were administered to all couples (experimental and control). To avoid order and sequence effects, the questionnaires were proposed following a Latin square design, in which the order was balanced within and between subjects.

The Behavioural Parent Training proposed to the experimental group aimed to teach parents a more effective management of inappropriate behaviour in their children. The training format included a series of themes that had to take place in a predetermined order, as they corresponded to a specific task analysis. Each session was repeated until all members of the group acquired these skills and were able to master them sufficiently. These were not academic lessons, in which information was simply forwarded about the most effective way to educate children, but practical exercises for the acquisition of specific educational skills.

The training programme was organised in 10 units. The first two sessions were devoted to familiarising the group and discussing common problems. The trainer gradually highlighted the timeliness of changing the perspective from which parents usually considered their children's behaviour, introducing, through examples and short videos, the principles and procedures of operant conditioning (or a functional analysis of behaviour). The next three sessions were dedicated to the acquisition of the appropriate use and contingent positive reinforcement techniques. Through modelling, role playing and feedback provided by the trainer, parents learned to pay attention and contingently reinforce their children's appropriate behaviours. At the end of each session, parents were provided with a reminder of what they had learned and monitoring sheets to fill in at home. The first part of each session consisted of a collective discussion about the difficulties and successes encountered during the week, so parents had the chance to meet each other and to model themselves under trainer supervision. After learning the use of educational techniques aimed at strengthening appropriate behaviours, over the next three sessions parents were gradually guided towards the acquisition of educative strategies to control their children's inappropriate behaviour. A session was devoted to the problem of compliance. Parents learned how to promote obedience and how to interact with the child in cases of oppositional behavioural patterns.

In the last sessions, parents learned to structure and implement a token economy programme and to use educative techniques for teaching their children new skills. This phase was of particular interest to parents because it allowed them to work more actively and with greater awareness with the rehabilitation therapist. In post-training, the assessment procedures carried out in pre-training were replicated in both groups of parents to evaluate the effect of the intervention on all outcomes measured.

\subsection{Results and Discussion}

Table 1 reports mean (M) and standard deviations (SD) of the scores obtained by parents, respectively, in pre-training and post-training.

To better compare the results and to normalise the distributions, all dates were transformed in sin-1 using the Freeman \& Tukey formula[57].

Analysis between the two groups of parents, carried out using the Mann-Whitney test[58], showed a significant difference in the recognition of problem behaviours exhibited by children in domestic situations (HSQ).

Table 1. Mean (standard deviation) scores of HSQ, PSQ and QVCE questionnaires for pre and post training

\begin{tabular}{|c|c|c|c|c|c|c|}
\hline \multirow{2}{*}{} & \multicolumn{2}{|c|}{ HSQ } & \multicolumn{2}{c|}{ PSQ } & \multicolumn{2}{c|}{ QVCE } \\
\cline { 2 - 7 } & Pre & Post & Pre & Post & Pre & Post \\
\hline $\begin{array}{c}\text { Parent training } \\
\text { group }\end{array}$ & .84 & .78 & .65 & .62 & .99 & 1.06 \\
$(.20)$ & $(.19)$ & $(.10)$ & $(.12)$ & $(.15)$ & $(.13)$ \\
\hline $\begin{array}{c}\text { Control } \\
\text { group }\end{array}$ & .77 & .83 & .64 & .67 & .96 & 1.00 \\
$(.24)$ & $(.28)$ & $(.15)$ & $(.15)$ & $(.16)$ & $(.12)$ \\
\hline
\end{tabular}

After attending the training programme, parents in the experimental group evaluated the behaviour of their children less negatively than the control group $(\mathrm{Z}=-2.2$., $\mathrm{P}<.05)$.

Figure 1 shows the average ratings expressed by parents during the pre-and post-training in HSQ.

Parents reported that the children did not actually present serious behavioural problems.

The values, shown in Figure 2, are not particularly high and there are no significant differences in the frequency of typical behaviours of conduct disorder (PSQ), since it remains almost constant even after the training. In fact, the comparison between pre-training and post-training, within the experimental group, carried out using Wilcoxon test[59], does not reveal a statistically significant reduction of 
behaviour associated with conduct disorders $(\mathrm{Z}=.78, \mathrm{p}$ $=.43)$, similarly to what occurs in the control group $(\mathrm{Z}=.91$, $\mathrm{p}=.36)$.

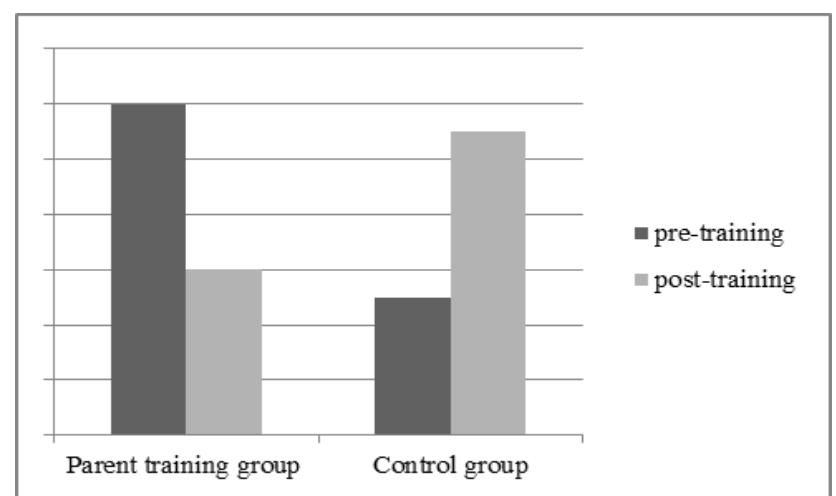

Figure 1. HSQ-Home Situations Questionnaire scores of parents in pre-training and post-training

Figure 2 shows the average scores for parents during the pre-and post-training in PSQ.

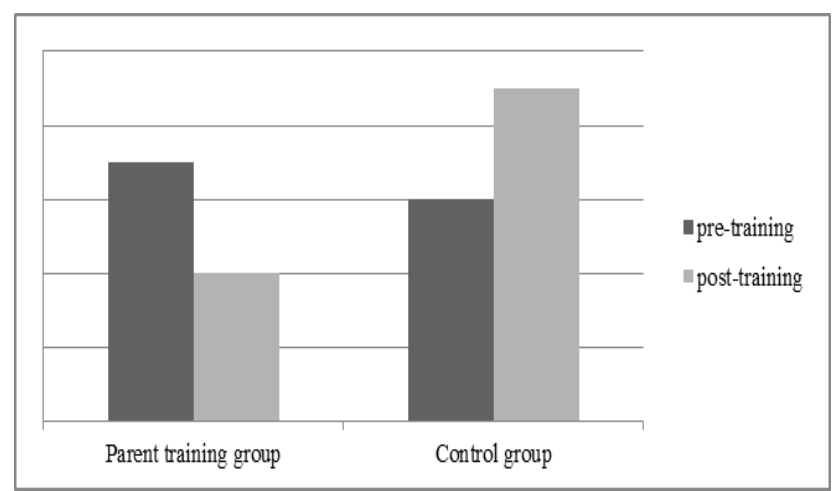

Figure 2. PSQ-Parent Symptom Questionnaire scores of parents in pre-training and post-training

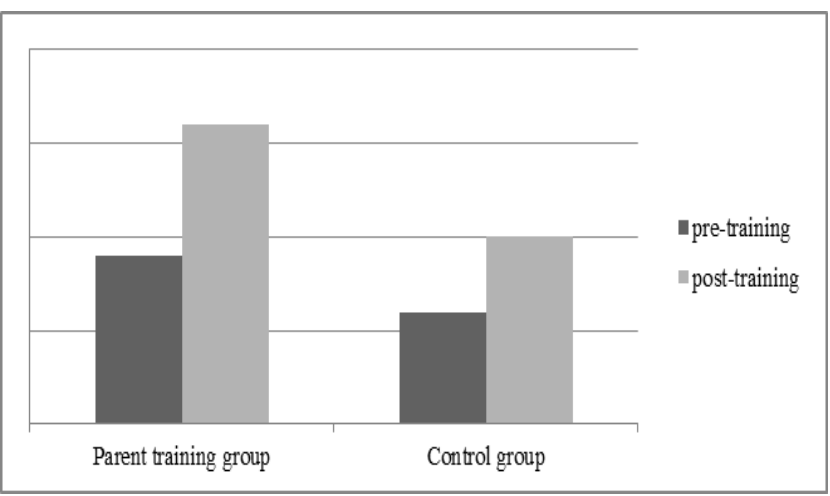

Figure 3. QVCE-Assessment Questionnaire of Educational Skills scores of parents in pre-training and post-training

The training seems to have improved parental competences in educative management. In fact, the educative skills of the parents who participated in the training improved significantly in post-training (pre vs. post $-\mathrm{Z}=2.1$, $\mathrm{p}<.05$ ), while they remained unchanged for the control group parents $(\mathrm{Z}=1.26, \mathrm{p}=.21)$. However, no significant differences between the experimental and control groups in post-training were recorded $(\mathrm{Z}=-1.22, \mathrm{p}=.22)$.
Figure 3 shows parents' educative skills (QVCE) in the experimental group and the control group, measured in pre-training and post-training.

Table 2 shows mean (M) and standard deviations (SD) of the scores obtained by the parents in the PSI questionnaire, in pre-training and post-training, respectively.

Table 2. Mean (standard deviation) scores of PSI questionnaire for pre and post training

\begin{tabular}{|c|c|c|c|c|c|c|}
\hline \multirow{2}{*}{} & \multicolumn{2}{|c|}{$\begin{array}{c}\text { Child } \\
\text { Domain }\end{array}$} & \multicolumn{2}{c|}{$\begin{array}{c}\text { Parent } \\
\text { Domain }\end{array}$} & \multicolumn{2}{c|}{$\begin{array}{c}\text { Total } \\
\text { Stress }\end{array}$} \\
\cline { 2 - 7 } & Pre & Post & Pre & Post & Pre & Post \\
\hline $\begin{array}{c}\text { Parent training } \\
\text { group }\end{array}$ & 1.08 & 1.02 & .91 & .90 & .99 & .95 \\
$(.08)$ & $(.09)$ & $(.07)$ & $(082)$ & $(.06)$ & $(.08)$ \\
\hline $\begin{array}{c}\text { Control } \\
\text { group }\end{array}$ & $\begin{array}{c}.99 \\
(.10)\end{array}$ & $\begin{array}{c}1.02 \\
(.12)\end{array}$ & $\begin{array}{c}.85 \\
(.11)\end{array}$ & $\begin{array}{c}.85 \\
(.11)\end{array}$ & $\begin{array}{c}.92 \\
(.10)\end{array}$ & $\begin{array}{c}.92 \\
(.10)\end{array}$ \\
\hline
\end{tabular}

A comparison of the two groups of parents, using the Mann Whitney test[58], showed significant differences in the various PSI sub-scales. In particular, differences between the groups (experimental and control) emerge only in the pre-training phase. In fact, the parents in the experimental group showed higher levels of stress in child domain $(\mathrm{Z}=$ $-1.9, \mathrm{p}=.048)$, parental domain $(\mathrm{Z}=2.30, \mathrm{p}=.02)$, and in the total score $(\mathrm{Z}=-2.25, \mathrm{p}=.02)$. However, no significant differences were found between the two groups in post-training[Child Characteristics: $\mathrm{Z}=-.069, \mathrm{p}=.95$; Parental distress: $Z=-1.4, p=.16$; Total Stress: $Z=-.76$, $p$ $=.45]$.

Figure 4 shows average levels of stress in the various PSI areas (Child Characteristics, Parental distress, Total Stress), in pre-and post-training.

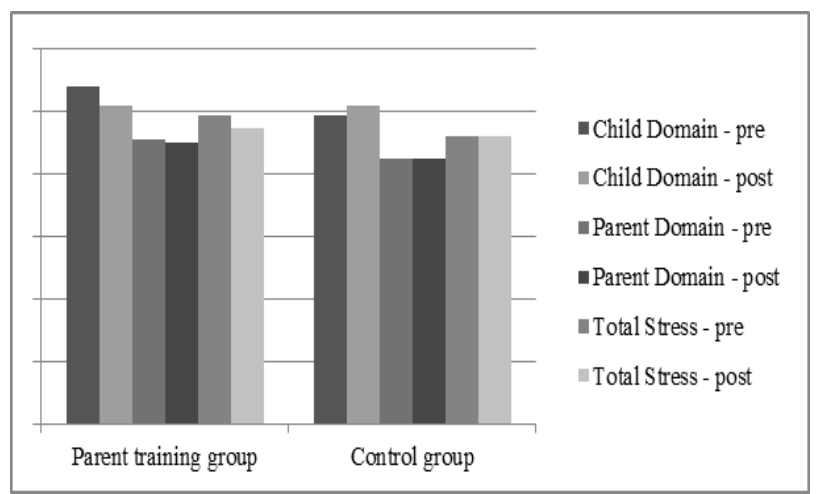

Figure 4. PSI Questionnaire scores of parents in pre-training and post-training

Simple comparisons within the groups showed that stress levels related to the child characteristics decreased significantly in the families who participated in parent training (pre vs. post: $-Z=-3.08, p<.002$ ). However, both parental stress $(Z=-.50, p=.61)$ and total stress $(Z=-2.01$, $\mathrm{p}=.44)$ remained high and no significant changes were noted. With regard to the control group, the comparisons between pre-training and post-training showed no significant differences in any of the PSI areas[Child Characteristics: $\mathrm{Z}=$ 
- .98, $\mathrm{p}=.33$; Parental Distress: $\mathrm{Z}=-.157, \mathrm{p}=.87$; Total Stress: $\mathrm{Z}=-.82, \mathrm{p}=.41]$.

\section{Conclusions}

Studies have shown that parents who complain about difficulties in educating and managing children with intellectual disabilities and behavioural problems are those who derive greater benefit from parent training. In fact, the sense of motivation and purpose that drive these groups of parents to undertake this programme and to invest their resources to improve their educative skills is crucial to the success of the intervention.

The aim of this research was to verify the effectiveness of parent training in the management of non-compliant behavior of mildly mentally retarded children. In particular, the training aimed to teach the appropriate use of behavioral techniques for identifying antecedents and consequences of non-compliant behavior, using appropriate reinforcement and punishment patterns.

It was considered useful to refer to the scores obtained by the parents in each of the measures adopted in the different assessment phases in order to determine whether, for the considered parameters (perception and evaluation of children problems, educational skills and parenting stress), the training brings about significant changes, compared to the baseline situation.

Due to certain obvious methodological shortcomings, mainly linked to the small sample size, the results cannot be generalized. However, this study can represent a further confirmation of the effectiveness of this parent training.

The parents trained in behavioral intervention modified the perception of their child's inappropriate behaviors and their confidence in parenting skills immediately increased after participating in the training program. This result is partly explained by the higher competence related to educative practices: parents were able to learn behavioral modification techniques and make informed decisions about which educative practices might be appropriate for their children's conduct. In the training sessions the experimental group learned educative techniques and put them into practice with their children in different interactive contexts.

The marked change in the evaluation of their children's improper conduct can also be explained by an increased ability in hoe they observe their child's behavior. In this sense, parents first learned to observe their child through the $\mathrm{ABC}$ models, which enabled them to note and highlight the child's skills and resources, as well as to distinguish between the difficulties closely related to their children's problems from those easily modified through the appropriate use of reinforcement techniques.

In addition, the parent training favoured a gradual reduction of total stress as well as that related to the child's characteristics and to the parental role. In particular, training seems to improve the parents' perception of the child's individual characteristics, previously considered possible sources of stress. Furthermore, the training appears to have impacted in a positive way on the parental role perception, improving the sense of inadequacy related to their responsibilities as caregivers. This is particularly true in family contexts where the presence of a child with special needs requires care, support and the parent's full and constant attention.

The parent training presented suggests several implications for future development of parent training and subsequent research. First, more emphasis should be placed on assessment, an essential element of parent training, particularly when related to children with complex disabilities. Second, though relying on parental reports, the present study suggests a decrease in the children's behavior problems at home. It would be interesting in future studies to assess the effect of this training on children's behavior in other contexts such as the school and using other forms of evaluation such as observational measures. In addition, an assumption of parent training is that children behaviors are influenced by parental functioning and perceptions. Results indicate that child behavior, parent stress, and parental perceptions were more adaptive at post-training than before treatment and families in the treatment group showed an advantage over control families. However, the absence of a follow up not helps to support for the maintenance of treatment benefits. The possible attenuation of effects over time underlines the need to engage families with difficult children in continuing care interventions which may help parents better maintain their skills and adjust them in response to developmental change[3].

While further confirming the effectiveness of behavioral parent training in the management of problematic children, the data evaluated give rise to new ideas and research perspectives. In fact, the option of extending the sample and providing for periodic follow-up sessions in order to verify the stability and the maintenance of the skills learned should certainly be taken into consideration. It would also be interesting to evaluate the hypothesis of extending the survey to variables not covered by the parent/child interaction, possibly investigating factors related more specifically to spousal relationships. Lack of parenting empowerment, in fact, may be particularly related to parents who are in conflict since they lack models for appropriate and effective parenting. Practitioners and therapists may wish also to explore this possibility when working with parents. This would facilitate a broader analysis of family functioning, thus providing, in a systemic perspective, more functional and helpful interventions.

In this context, the direct involvement of both members of a couple in parent training is undoubtedly an added strength in any type of preventive program for improving the educative management and, consequently, the quality of family functioning, both as a couple and a nucleus. 


\section{REFERENCES}

[1] Forehand R., McMahon R.J., Helping the non-compliant child: A clinician's guide to effective parent training. Guilford Press, New York, 1981.

[2] Forehand R., Wierson M., "The role of developmental factors in planning behavioral interventions for children: Disruptive behavior as an example." Behavior Therapy, vol. 24, n.1, pp.117-141, 1993.

[3] Lundahl B.W., Risser H.J., Lovejoy C., "A meta-analysis of parent training: Moderators and follow-up effects." Clinical Psychology Review, vol. 26, n 1, pp. 86-104, 2006.

[4] Mathias J., Mertin P., Murray A., "The psychological functioning of children from backgrounds of domestic violence." Australian Psychologist, vol. 30, $\mathrm{n}^{\circ} .1, \mathrm{pp} .47-56$, 1995.

[5] Mertin P., Mathias J., Children of Domestic violence: Effects on Behavioural Emotional and Psychological functioning, South Australian Department of Family and Community Services, Adelaide, 1991.

[6] Patterson G.R., Coercitive family systems. Eugene, Castalda, OR, 1982 .

[7] Larcan R., "Un progetto di intervento per la prevenzione di problemi comportamentali in età evolutiva." In: A. Ma. Di Vita, R. Larcan (a cura di), Crescere nella complessità, Unicopli, Milano, 1998.

[8] Matson J.L., Mahan S., Lo Vullo S.V., "Parent training: A review of methods for children with developmental disabilities.", Research in Developmental Disabilities, vol.30, n5, pp. 961-968, 2009.

[9] Sattler J.M., Assessment of children: Behavioural and clinical applications (4th ed.). Jerome M. Sattler, Inc. San Diego, CA, 2002.

[10] Weiss J., Sullivan A., Diamond T., "Parent stress and adaptive functioning of individuals with developmental disabilities", Journal of Developmental Disabilities, vol.10, $\mathrm{n}^{\circ} 1$,pp. 129-136, 2003.

[11] Hauser-Cram P., Warfield M.E., Shonkaff J.P., Krauss M.W., "A longitudinal study of child development and parent well-being.", Monographs of the Society of Child Development, vol.66, n³, pp. 266, 2001.

[12] Dyson L.L., "Families of young children with handicaps: Parental stress and family functioning.", American Journal on Mental Retardation, vol.95, n6, pp. 623-629, 1991.

[13] Larcan R., Oliva P., Sorrenti L., Interventi psicologici sulla famiglia. Piccin Nuova libraria, Padova, 2008.

[14] Helm D.T., Kozloff M.A., "Research on parent training, shortcomings and remediation.", Journal of Autism and Developmental Disorders, vol.16, n¹, pp.1-20, 1986.

[15] Friedrich W.N., Friedrich W.L., "Psychosocial assets of parents of handicapped and non-handicapped children." American Journal of Mental Deficiency, vol.85, n 2, pp.551-553, 1981.

[16] Gallagher J.J., Beckman P., Cross A.H., "Families of handicapped children: source of stress and its amelioration." Exceptional Children, vol. 50, pp. 10-19, 1983.

[17] Cuzzocrea F., Larcan R., "Funzionamento della famiglia e sviluppo psico-sociale dei fratelli di individui con disabilità intellettive”. Psicologia Clinica dello Sviluppo, vol.XV, $\mathrm{n}^{\circ} 1$, pp. 123-153, 2011.

[18] Podolski C., L.e Nigg J.T., "Parent stress and coping in relation to child ADHD severity and associated child disruptive behavior problems." Journal of Clinical Child Psychology, vol.30, nº4, pp. 503-513, 2001.

[19] Fabiano G.A., "Father participation in behavioral parent training for ADHD: review and recommendations for increasing inclusion and engagement." Journal of Family Psychology, vol.21, n4, pp. 683-693, 2007.

[20] Kumpfer K.L., Strengthening America's Families: Exemplary Parenting and Family Strategies For Delinquency Prevention. User's Guide prepared under Grant No. 95-JN-FX-K010 from the Office of Juvenile Justice and Delinquency Prevention, 1-55. Office of Juvenile Programs, U.S. Department of Justice, 1999.

[21] Barlow J.H., Systematic review of the effectiveness of parent-training programs in improving the behavior of 3-7 year old children. Health Services Research Unit Report, Oxford, 1997.

[22] Barlow J.H., Powell L.A., Gilchrist M., Fotiadou M., "The effectiveness of the Training and Support Program for parents of children with disabilities: A randomized controlled trial." Journal of Psychosomatic Research, vol.64, n¹, pp. 55- 62, 2008.

[23] Ducharme J.M., Harris K., Milligan K., Pontes E., "Sequential Evaluation of Reinforced Compliance and Graduated Request Delivery for the Treatment of Non-compliance in Children with Developmental Disabilities." Journal of Autism and Developmental Disorders, vol.33, n5, pp. 519-526, 2003.

[24] Benedetto L., Il parent training: counseling e formazione per genitori. Carocci, Padova, 2005.

[25] Serketich W.J., Dumas J.E., "The effectiveness of behavioral parent training to modify antisocial behavior in children: A meta-analysis”. Behavior Therapy, vol.27, n², pp. 171-186, 1996.

[26] Ducharme J.M., Atkinson L., Poulton L., "Success-based, non-coercive treatment of oppositional behavior in children from violent homes." Journal of the American Academy of Child and Adolescent Psychiatry, vol.39, n8, pp. 995-1004, 2000 .

[27] Briesmeister J.M., Schaefer C.E., Handbook of Parent Training. Parents as co-therapists for children's behavior problems (2nd ed.). John Wiley \& Sons, Chichester, 1998.

[28] Rutter M., "Psychosocial resilience and protective factors." In: J. Rolf, A.S. Masten, D. Cicchetti, K.H. Nuechterlein, S. Weintraub (Eds.) Risk and protective factors in the development of psychopathology. Cambridge University Press, New York, 1990.

[29] Lochman J.E., Wayland K.K., "Aggression, social acceptance and race as predictors of negative adolescent outcomes." Journal of the American Academy of Child and Adolescent Psychiatry, vol.33, n 1 , pp. 1026-1035, 1994.

[30] DuPaul G.J., McGoey K.E., Eckert T.L., VanBrakle, J., "Preschool children with attention-deficit/hyperactivity disorder: Impairments in behavioral, social, and school functioning." Journal of the American Academy of Child and Adolescent Psychiatry, vol.40, n5, pp. 508-515, 2001. 
[31] Matson J.L., Smith K.R., "Current status of intensive behavioral interventions for young children with autism and PDD-NOS." Research in Autism Spectrum Disorders, vol.2, n¹, pp. 60-74, 2008.

[32] Matson J.L., Wilkins J., Gonzalez M.L., "Early identification and diagnosis of autism spectrum disorders in young children and infants. How early is too early?" Research in Autism Spectrum Disorders, vol. 2, $\mathrm{n}^{\circ} 1$, pp. 75-84, 2008.

[33] Kazdin A.E., "Treatment of conduct disorder: Progress and directions in psychotherapy research." Development and Psychopathology, vol. 5, n¹-2, pp. 277-310, 1993.

[34] Kazdin A.E., "Parent management training: Evidence, outcomes, and issues." Journal of the American Academy of Child and Adolescent Psychiatry, vol. 36, n 10 , pp. 13491356, 1997.

[35] Kazdin A.E., Parent Management Training: Treatment for Oppositional Aggressive, and Antisocial Behavior in Children and Adolescents. New York: Oxford University Press, 2005.

[36] Ducharme J.M., "Errorless compliance training: Optimizing clinical efficacy." Behavior modification, vol.20, $\mathrm{n}^{\circ} 3$, pp. 259-280, 1996.

[37] Reid M.J., Webster-Stratton C., Hammond M., "Follow up of children who received the Incredible Years Intervention for oppositional defiant disorder: Maintenance and prediction of 2-year outcome." Behavioral Therapy, vol. 34, nº 4 , pp. 471-491, 2003.

[38] Lochman J.E., Wells K.C., "Contextual social-cognitive mediators and child outcome: A test of the theoretical model in the Coping Power program." Development and Psychopathology, vol.14, n4, pp. 945-967, 2002.

[39] Singh N., Singh A.N., Lancioni, G.E., Singh J., Winton A., Adkin A.D., "Mindfulness Training for Parents and Their Children With ADHD Increases the Children's Compliance." Journal of Child and Family Studies, vol.19, n², pp. 157-166, 2010.

[40] Ducharme J.M., Spencer T., Davidson A., Rushford N., "Errorless compliance training: Building a cooperative relationship between brain-injured parents at risk for maltreatment and their oppositional children." American Journal of Orthopsychiatry, vol.72, n 4 , pp. 585-595, 2002.

[41] Baer D.M., Wolf M.M., Risely T.R., "Some current dimensions of applied behavior analysis." Journal of Applied Behavior Analysis, vol.1, n¹, pp. 91-97, 1968.

[42] Skinner B.F., Science and Human Behavior. New York: McMillan, 1953.

[43] Bandura A., Social Learning Theory. Englewood Cliffs, NJ: Prentice-Hall, 1977.

[44] France K.G., Hudson S.M., "Behavior management of infant sleep disturbance." Journal of Applied Behavior Analysis, vol.23, n 1 , pp. 91-98, 1990.

[45] Reid M.J., Walter A.L., O’Leary S.G., "Treatment of young children's bedtime refusal and night-time waking: A comparison of "standard" and graduated ignoring procedures."
Journal of Abnormal Child Psychology, vol.27, n 1 , pp. 5-16, 1999.

[46] Scott S., Parent training programs. In Rutter M, Taylor E, eds. Child and adolescent psychiatry. 4th ed. Oxford: Blackwell Science, 2002.

[47] Sampson R.J., Lamb J.H., "Urban poverty and the family context of delinquency. A new look at structure and process in a classic structure." Child Development, vol.65, $\mathrm{n}^{\circ} 1, \mathrm{pp}$. 523-540, 1994

[48] Yoshikawa H., "Prevention as cumulative protection: Effects of early family support and education on chronic delinquency and its risks." Psychological Bulletin, vol.115, n 1 , pp. 28-54, 1994.

[49] Mindell J.A., Durand V.M., "Treatment of childhood sleep disorders: Generalization across disorders and effects on family members." Journal of Pediatric Psychology, vol.18, n¹, pp. 731-750, 1993

[50] Singer G.H.S., Ethridge B.L., Aldana S.I., "Primary and secondary effects of parenting and stress management interventions for parents of children with developmental disabilities: A meta-analysis." Mental Retardation and Developmental Disabilities Research Reviews, vol. 13, $\mathrm{n}^{\circ} 1$, pp. 357-369, 2007.

[51] Hiscock H., Wake M., "Randomized controlled trial of behavioral infant sleep intervention to improve infant sleep and maternal mood." British Medical journal, vol.324, n², pp. 1062-1065, 2002.

[52] Barkley R.A., Edelbrock C.S., Assessing situational variation in children's behavior problems: The Home and School Situations Questionnaires. In R. Prinz (Ed.), Advances in behavioral assessment of children and families (Vol. 3, pp. 157-176). Greenwich, CV. JAI Press, 1987.

[53] Conners C.K., "Parent Symptom Questionnaire." Psychopharmacology Bulletin, vol.21, $\mathrm{n}^{\circ} 1$, pp. 816-822, 1985.

[54] Cuzzocrea F., Larcan R., Oliva P., "Parent training for families with mentally retarded children." International Journal of Psychology, vol.43, n³/4, pp. 309, 2008.

[55] Cuzzocrea F., Filippello G., Costa S., Larcan, R., (under review) How to handle the discipline: a Questionnaire for the Evaluation of Parents' Educational Skills. Educational Assessment.

[56] Abidin R.R., Parent Stress Index. Third Edition. Psychological Assessment Resources, Inc., Florida, 1995.

[57] Freeman M.F., Tukey J.W., "Transformation related to angular and square root." Annuals of Mathematics and Statistics, vol.21, n4, pp. 607, 1950.

[58] Mann B., Whitney D.R., "On a Test of Whether one of Two Random Variables is Stochastically Larger than the Other." Annals of mathematical statistics, vol.18, $\mathrm{n}^{\circ} 1$, pp. 50-60, 1947.

[59] Wilcoxon F., "Individual comparison by ranking methods." Biometrics Bulletin, vol.1, n6, pp. 80-83, 1945. 